\title{
Effect of indomethacin on cerebral blood flow, carbon dioxide reactivity and the response to epoprostenol (prostacyclin) infusion in man
}

\author{
HILARY PICKLES, ${ }^{*}$ MM BROWN, MYFANWY THOMAS, $\dagger$ AH HEWAZY, SHEILA \\ REDMOND, E ZILKHA, J MARSHALL
}

From the Institute of Neurology, Queen Square, London, UK

SUMMARY Cerebral blood flow (CBF) has been measured using a non-invasive Xenon ${ }^{133}$ clearance technique in six normal subjects after 2 days pretreatment with oral indomethacin at a dose of $100 \mathrm{mg} /$ day. The results were compared with placebo given in a double blind balanced cross-over design. Indomethacin was found to result in a reduction in resting CBF of about $25 \%$ but the reactivity of the cerebrovascular circulation to carbon dioxide was preserved at normal levels. Infusions of epoprostenol (prostacyclin, $\mathrm{PGI}_{2}$ ) at a dose of $5 \mathrm{ng} / \mathrm{kg} / \mathrm{min}$ resulted in a reduction of $\mathrm{CBF}$ of about $10 \%$ after placebo but no significant change in CBF after indomethacin. The results suggest that prostaglandins are involved in the maintenance of cerebrovascular tone but not in the mechanism of cerebral vasodilation accompanying hypercapnia. The combination of indomethacin and $\mathrm{PGI}_{2}$ has been proposed as a treatment of cerebral artery spasm and the findings suggest that the combination therapy would not be accompanied by undesirable intracerebral steal.

There is considerable evidence, recently reviewed by Pickard, ${ }^{1}$ which suggests that prostaglandins and particularly prostacyclin (epoprostenol, $\mathrm{PGI}_{2}$ ) are involved in the control of cerebral blood flow (CBF). The evidence comes from two separate lines, firstly experiments on the effects of indomethacin used as an inhibitor of prostaglandin synthesis, and secondly animal experiments on the direct effects of PGI, both in vitro and in vivo. Pickard and Mackenzie $^{2}$ first showed that in baboons intraarterial indomethacin reduced resting $\mathrm{CBF}$, and almost abolished the rise in CBF that normally results from hypercapnia. Similar findings were recently reported in humans studied 1 hour after

\footnotetext{
${ }^{*}$ Present address: Medicines Division, DHSS, Market Towers, 1 Nine Elms Lane, London SW8 5NQ, UK.

†Present address: Department of Neurology, Institute of Neurological Sciences, Southern General Hospital, 1345 Govan Road, Glasgow G51 4TF, UK.
}

Address for reprint requests: Dr MM Brown, National Hospital for Nervous Diseases, Queen Square, London WC1N 3BG, UK.

Received 9 March 1983 and in revised form 8 July 1983. Accepted 17 July 1983 rectal indomethacin. ${ }^{3}$ These results were taken as evidence that some endogenous prostaglandin was involved in the CBF response to hypercpania and from the very rapid onset of the effect of indomethacin it was concluded that a prostaglandin with a very rapid turnover was involved in CBF regulation. Prostacyclin (epoprostenol, $\mathrm{PGI}_{2}$ ) appeared to have the required characteristics. It is formed by vascular endothelium ${ }^{4}$ and can be produced in vitro by cerebral vessels. ${ }^{56}$ It is a potent vasodilator, reducing vascular resistance when given systemically, ${ }^{7}$ and dilates human cerebral vessels in vitro ${ }^{5}$ When given into the carotid artery of baboons in high concentrations, $\mathrm{PGI}_{2}$ increases $\mathrm{CBF} .{ }^{8} \mathrm{PGI}_{2}$ also has the required short half-life in vivo of only a few minutes. There has also been interest in $\mathrm{PGI}_{2}$ as a potential therapeutic agent in ischaemic cerebral conditions. Cerebral artery spasm following subarachnoid haemorrhage may be a particular indication, ${ }^{5}$ as in animals $\mathrm{PGI}_{2}$ can overcome this spasm in vitro $^{59}$ and in vivo. ${ }^{10}$ The combination of indomethacin and $\mathrm{PGI}_{2}$ was found to increase $\mathrm{CBF}$ after cerebral ischaemia in dogs. ${ }^{11}$

There are a number of discrepancies in the evidence implicating $\mathrm{PGI}_{2}$ in the control of CBF. Firstly agents other than indomethacin that also inhibit 
prostaglandin synthesis appear unable to block the $\mathrm{CBF}$ response to hypercapnia (eg aspirin given acutely $^{12}$ or chronically ${ }^{13}$ ). Secondly Brown and Pickles $^{14}$ in an earlier study investigated the effect of intravenous $\mathrm{PGI}_{2}$ in normal subjects at the highest concentration that can be comfortably tolerated by conscious humans and, in contrast to the animal studies using higher concentrations, found that CBF was slightly reduced after $\mathrm{PGI}_{2}$. One explanation of this finding could be that the normal cerebral circulation did not dilate in response to exogenous PGI ${ }_{2}$ because of a rapid resetting of the normal balance between dilator and constrictor influences involving other prostaglandins. To investigate this possibility we have studied the effect of $\mathrm{PGI}_{2}$ on CBF in normal human subjects before and after indomethacin pretreatment. We have also investigated the effects of indomethacin on resting CBF and the CBF response to hypercapnia. A dose of oral indomethacin was used that is adequate to reduce endogenous prostaglandin synthesis ${ }^{15}$ without producing other toxic effects.

\section{Methods}

Six normal subjects, three male, three female, aged 20-23 years took part in this study which had been approved by the Ethics Committee of the National Hospital, Queen Square. Each subject was studied on two occasions, which were separated by at least 2 weeks. Prior to attending the laboratory the subjects took either oral indomethacin $100 \mathrm{mg}$ daily for 3 days in divided doses, with $50 \mathrm{mg}$ on the morning of the experimental day, or matching placebo capsules according to a double-blind, balanced cross-over design. On each experimental day the subjects had thre $\epsilon$ measurements of CBF separated by at least 40 minutes and in the same sequence (1) at rest during normocapnia, (2) while breathing $5 \%$ or $8 \%$ carbon dioxide $\left(\mathrm{CO}_{2}\right)$ in air and (3) during an infusion of $\mathrm{PGI}_{2} . \mathrm{PGI}_{2}$, synthesised by Upjohn and formulated by the Wellcome Foundation was diluted in glycine buffer at $\mathrm{pH} 10.5$ and given by constant infusion pump into a forearm vein at a dose of $5 \mathrm{ng} / \mathrm{kg} / \mathrm{min}$ for 5-10 minutes prior to and throughout the third CBF estimation.

CBF was measured by the non-invasive intravenous Xenon ${ }^{133}\left(\mathrm{Xe}^{133}\right)$ clearance technique, details of which are given elsewhere..$^{16} \mathrm{In}$ brief, a bolus of approximately $7 \mathrm{mCi}$ of $\mathrm{Xe}^{133}$, dissolved in saline, was injected into a forearm vein and the clearance of the isotope from the cerebral hemispheres monitored for 15 minutes with six external $25 \mathrm{~mm}$ diameter scintillation detectors. Expired concentrations of $\mathrm{Xe}^{133}$ were monitored with a seventh detector and the end-tidal levels used to estimate recirculating arterial $\mathrm{Xe}^{133}$ concentrations. Regional CBF was calculated from a bicompartment analysis of 11.5 minutes of the clearance data and also from an initial slope analysis of the first 1 minute of the clearance curves. These analyses resulted in figures for volumetric blood flow through the fast clearing tissues of the brain which are mainly grey matter ( $F$ fast), and a figure for flow to the whole brain ( $F$ init). To reduce the subjects' exposure to $\mathrm{CO}_{2}$, isotope clearance during hypercapnia was monitored for only five minutes and the measurements of $\mathrm{CBF}$ while breathing $\mathrm{CO}_{2}$ were therefore limited to an initial slope analysis only. The CBF values used for each subject were the means of the six regional measurements.

Blood pressure was recorded from the left arm with a standard mercury sphygmomanometer and the pulse rate measured over 30 seconds from the radial pulse on three occasions during the CBF measurement. Arterial partial pressure of carbon dioxide $\left(\mathrm{pCO}_{2}\right)$ was estimated by monitoring expiratory $\mathrm{CO}$ concentration with a Datex $\mathrm{CD}$ 300 infra red analyser. The $\mathrm{pCO}_{2}$ levels were calculated from the mean end tidal concentration over the first 5 minutes of each study. Samples were taken for estimation of indomethacin blood levels at the start of the first and third CBF estimations on each study day, and were analysed by a modification of the spectrofluorometric method of Hucker. ${ }^{17}$

\section{Results}

The CBF results are shown in the table. Baseline resting CBF was found to be reduced by about $25 \%$ following indomethacin pretreatment compared to placebo $(p<0.02)$. These results and the response to hypercapnia are illustrated in the figure. Hypercapnia caused a significant rise in CBF ( $p$ $<0.01)$ both after indomethacin and placebo pretreatments but there was no significant difference in the responses with the two pretreatments. The mean $\%$ reactivity to $\mathrm{CO}_{2}$ (\% rise in $\mathrm{CBF}$ with each $\mathrm{kPa}$ rise in $\mathrm{pCO}_{2}$ ) was 34.7 on placebo and 33.7 on indomethacin.

The infusion of $\mathrm{PGI}_{2}$ resulted in a small reduction in $\mathrm{CBF}$ of about $10 \%$ following placebo treatment compared to the baseline levels $(p<0.05)$. In contrast, following indomethacin treatment there was no significant change in CBF. There was no significant difference in the $\mathrm{pCO}_{2}$ measurements between indomethacin and placebo pretreatment either during the resting measurement or after $\mathrm{PGI}_{2}$. The patterns of end-tidal $\mathrm{Xe}^{133}$ concentration were not significantly altered by the $\mathrm{PGI}_{2}$ infusions and it is therefore unlikely that there were significant alterations in the ratio of arterial to expired $\mathrm{Xe}^{133}$ concentrations that might have influenced the accuracy of the correction for arterial recirculation.

Indomethacin produced no significant differences in heart rate or blood pressure compared to placebo at normocapnia, hypercapnia or during PGI. However, within each treatment group, $\mathrm{PGI}_{2}$ infusion caused a small rise in heart rate, mean increase 9.4 beats/min on placebo, 6.8 on indomethacin ( $p$ $<0.05$ cf baseline). There was no significant change in systolic blood pressure during $\mathrm{PGI}_{2}$, but diastolic 
Table Effect of indomethacin on cerebral blood flow in six subjerts

\begin{tabular}{|c|c|c|c|c|c|c|c|c|}
\hline & \multicolumn{4}{|c|}{ Placebo mean $\pm S E M$} & \multicolumn{4}{|c|}{ Indomethacin mean $\pm S E M$} \\
\hline & \multicolumn{2}{|c|}{$\begin{array}{l}\text { Cerebral blood flow } \\
\mathrm{ml} / 100 \mathrm{mg} / \mathrm{min}\end{array}$} & \multirow[t]{2}{*}{$\begin{array}{l}p \mathrm{CO}_{2} \\
k P a\end{array}$} & \multirow{2}{*}{$\begin{array}{l}\text { Systolicl } \\
\text { diastolic } \\
\text { blood pressure } \\
\text { mm Hg }\end{array}$} & \multicolumn{2}{|c|}{$\begin{array}{l}\text { Cerebral blood flow } \\
\mathrm{ml} / 100 \mathrm{mg} / \mathrm{min}\end{array}$} & \multirow[t]{2}{*}{$\begin{array}{l}p \mathrm{CO}_{2} \\
k \mathrm{~Pa}\end{array}$} & \multirow{2}{*}{$\begin{array}{l}\text { Systolic/ } \\
\text { diastolic } \\
\text { blood pressure } \\
\text { mm } \mathrm{Hg}\end{array}$} \\
\hline & Ffast & Finit & & & Ffast & Finit & & \\
\hline \multirow{2}{*}{$\begin{array}{l}\text { (1) Baseline } \\
\text { normocapnia } \\
\text { (2) Hypercapnia } \\
\text { (3) PGI }{ }_{2} \text { infusion } \\
\text { (normocapnia) }\end{array}$} & $\emptyset_{\emptyset}^{81 \cdot 6 \pm 4 \cdot 4}$ & $\begin{array}{l}58 \cdot 3 \pm 4 \cdot 1 \\
88 \cdot 0 \pm 5 \cdot 2 \ddagger\end{array}$ & $\begin{array}{l}5.4 \pm 0.16 \\
7.0 \pm 0.26\end{array}$ & $\begin{array}{l}113 \cdot 4 / 74 \cdot 7 \\
119 \cdot 2 / 76 \cdot 6\end{array}$ & $g^{60 \cdot 7 \pm 3 \cdot 0 \dagger}$ & $\begin{array}{l}43 \cdot 3 \pm 1 \cdot 7 \dagger \\
71 \cdot 9 \pm 7 \cdot 4 \ddagger\end{array}$ & $\begin{array}{l}5.24 \pm 0.17 \\
7.0 \pm 0.32\end{array}$ & $\begin{array}{l}117 \cdot 2 / 75 \cdot 8 \\
121 \cdot 2 / 81 \cdot 7\end{array}$ \\
\hline & $73.7 \pm 3.6^{*}$ & $53 \cdot 3 \pm 3 \cdot 5$ & $5 \cdot 25 \pm 0 \cdot 14$ & $117 \cdot 3 / 67 \cdot 6^{*}$ & $66 \cdot 4 \pm 2 \cdot 8$ & $46 \cdot 5 \pm 2 \cdot 0$ & $5.3 \pm 0.19$ & $117 \cdot 3 / 67 \cdot 8^{*}$ \\
\hline
\end{tabular}

$* \mathrm{p}<0.05$ paired $t$ test, cf baseline placebo.

$+\mathrm{p}<0.02$ paired $t$ test, cf baseline placebo.

$\ddagger \mathrm{p}<0.01$ paired $t$ test, cf normocapnia.

$\emptyset$ Ffast not obtained during hypercapnia.

pressure fell by a mean of $7 \mathrm{~mm} \mathrm{Hg}$ following placebo, and $8 \mathrm{~mm} \mathrm{Hg}$ following indomethacin ( $\mathrm{p}$ $<0.05$ of baseline). All subjects exhibited facial flushing during $\mathrm{PGI}_{2}$ and headache was experienced in 11 out of the 12 infusions. Other adverse effects seen on one occasion each were restlessness, palmar flushing, lightheadedness, and palpitations. One subject described stiffness and pain in the jaw: this unusual response to $\mathrm{PGI}_{2}$ has not previously been reported in a normal volunteer but is well recognised in patient studies. ${ }^{18}$ Mean blood levels of indomethacin were $1.4 \mu \mathrm{g} / \mathrm{ml}$ at the time of the first (baseline) CBF estimation on the indomethacin day, and $0.5 \mu \mathrm{g} / \mathrm{ml}$ by the time of the third $\left(\mathrm{PGI}_{2}\right) \mathrm{CBF}$ estimation approximately 2 hours later.

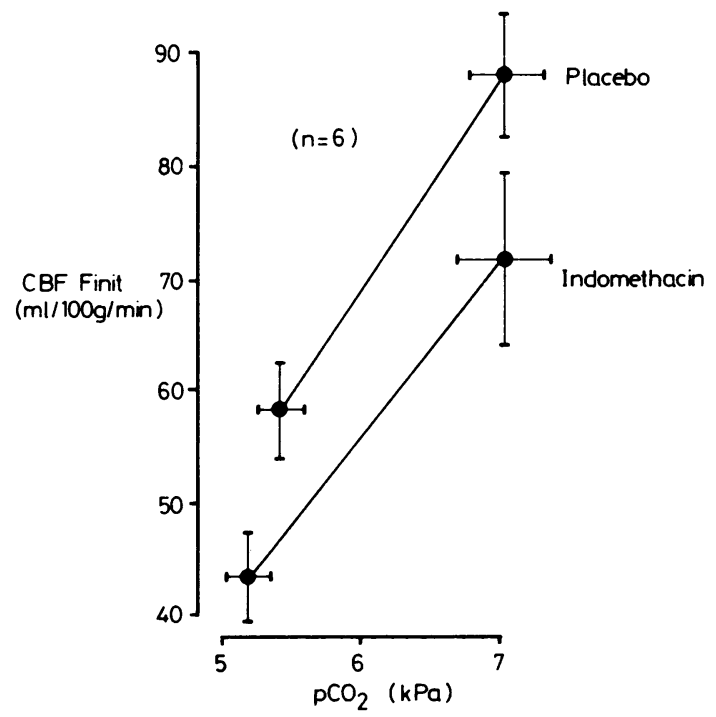

Fig Effect of hypercapnia on cerebral blood flow following placebo and oral indomethacin. Means \pm SEM.

\section{Discussion}

This study has confirmed that oral indomethacin reduces resting CBF in man. Since Vane's discovery of its effect as an inhibitor of prostaglandin synthesis, ${ }^{19}$ indomethacin has been used as a standard pharmacological tool in prostaglandin research. If an action is blocked or inhibited by indomethacin, this is often taken as suggestive evidence that endogenous prostaglandins are involved in the reaction. On this basis we could conclude that a vasodilatory endogenous prostaglandin is involved in the regulation of normal human $\mathrm{CBF}$, and $\mathrm{CBF}$ falls following indomethacin because the dominant dilator prostaglandin tone is removed. This has been the argument put forward by Pickard ${ }^{12}$ and others ${ }^{3}$ based on similar work on the effects of acute indomethacin administration to man and animals. However, some other inhibitors of prostaglandin synthesis such as aspirin ${ }^{12}$ and naproxen ${ }^{20}$ are without effect on resting CBF when given chronically, and Eriksson $e t$ al $^{21}$ reported that a week of oral indomethacin does not reduce resting CBF in man. The position is thus unclear and although our results are compatible with the prostaglandin hypothesis, further evidence is required.

The current study has also demonstrated that pretreatment with oral indomethacin does not alter the normal cerebrovascular response to an increase in arterial $\mathrm{pCO}_{2}$. This is in contrast to the conclusions of two previous studies, which have suggested that indomethacin reduces cerebral vasodilation during hypercapnia in $\operatorname{man}^{3}$ and the baboon. ${ }^{2}$ However, both these studies examined the effects of acute administration of indomethacin, rather than two days pretreatment, and this may explain the results. There are also other methodological differences between the studies which may be relevant. The normal CBF response to an increase in arterial $\mathrm{pCO}_{2}$ is exponential and also varies considerably 
from one individual to another. ${ }^{22}$ It is therefore essential to express $\mathrm{CO}_{2}$ reactivity for each subject as a percentage of baseline values. It is not possible to calculate $\mathrm{CO}_{2}$ reactivity accurately in the previous human study ${ }^{3}$ because of different numbers of subjects in the normocapnic and hypercapnic groups and therefore the results cannot be directly compared to ours. In the baboon study ${ }^{2}$ much higher doses of indomethacin were given directly into the circulation and the results could have been due to a toxic effect of the drug. Our current study suggests that prostaglandins are not directly involved in the mechanism of cerebral vasodilation accompanying hypercapnia and this is supported by the recent demonstration that an increase in $\mathrm{PGI}_{2}$ metabolites is not found in the cerebral circulation during hypercapnia. ${ }^{20}$ The mediator of the dilatory response to hypercapnia is still unknown and suitable alternatives should be sought.

The finding that $\mathrm{PGI}_{2}$ reduces $\mathrm{CBF}$ slightly after placebo pretreatment in normal individuals confirms previous studies. ${ }^{143}$ Exogenous $\mathrm{PGI}_{2}$ greatly reduces peripheral resistance ${ }^{7}$ and there is considerable shunting of blood through the GI tract. ${ }^{24} 25$ The increase in cardiac output ${ }^{7}$ does not match this fully, and a small drop in blood pressure usually results, which could result in reduced CBF. However, the cerebral circulation is normally protected by the process of autoregulation from fluctuations in perfusion pressure and we have therefore previously suggested ${ }^{14}$ that $\mathrm{PGI}_{2}$ may result in a disturbance of autoregulation. However, the finding that $\mathrm{CBF}$ remained unchanged and if anything rose in response to $\mathrm{PGI}_{2}$ infusion after indomethacin pretreatment despite equivalent falls in blood pressure makes this suggestion less likely. Taken together the results suggest that exogenous $\mathrm{PGI}_{2}$ has a direct effect on cerebrovascular tone which is dependent on the overall level of other prostaglandins.

Although $\mathrm{PGI}_{2}$ in doses acceptable to conscious humans does not appear to increase the normal level of $\mathrm{CBF}$ this does not exclude a therapeutic vasodilator role in pathological areas of the circulation. $\mathrm{PGI}_{2}$ is able to overcome cerebral artery spasm in vitro $^{59}$ and in vivo ${ }^{10}$ and may therefore have a place in the treatment of subarachnoid haemorrhage. In dogs modest doses of $\mathrm{PGI}$, increase $\mathrm{CBF}$ to ischaemic areas of brain only after indomethacin pretreatment. " The current studies have shown that combined treatment with $\mathrm{PGI}_{2}$ and indomethacin in patients with cerebrovascular disease would not result in significant vasodilation in normal areas of the brain and would therefore be unlikely to cause undesirable intra cerebral steal of blood away from ischaemic to normal areas.
We thank Wellcome Research Laboratories for $\mathrm{PGI}_{2}$ and financial support, and our volunteers for their assistance. HP was supported by the MRC, $\mathrm{MMB}$ and $\mathrm{AHH}$ were research fellows in cerebral blood flow at the Institute of Neurology and MT was supported by the Greater Glasgow Health Board. Indomethacin assays were performed for us by Ms Pauline Hill, Department of Clinical Pharmacology, St Bartholomew's Hospital, London.

\section{References}

' Pickard JD. Role of prostoglandins and arachidonic acid derivatives in the coupling of cerebral blood flow to cerebral metabolism. J Cereb Blood Flow Metab 1981;1:361-84.

2 Pickard JD, Mackenzie ET. Inhibition of prostaglandin synthesis and the response of baboon cerebral circulation to carbon dioxide. Nature 1973;245:187-8.

${ }^{3}$ Wennmalm $\AA$, Eriksson S, Wahren J. Effect of indomethacin on basal and carbon dioxide stimulated cerebral blood flow in man. Clin Physiology $1981 ; 1: 227-34$.

${ }^{4}$ Herman AG, Moncada S, Vane JR. Formation of prostacyclin $\left(\mathrm{PGI}_{2}\right)$ by different layers of the arterial wall. Arch Int Pharmacodyn Ther 1977;277:162-3.

${ }^{5}$ Boullin DJ, Bunting S, Blaso WP, Hunt TM, Moncada S. Responses of human and baboon arteries to prostaglandin endoperoxides and biologically generated and synthetic prostacyclin: their relevance to cerebral artery spasm in man. $\mathrm{Br} J$ Clin Pharmacol 1979;7:139-47.

${ }^{6}$ Hagan AA, White RP, Robertson JP. Synthesis of prostaglandins and thromboxane $\mathrm{B}_{2}$ by cerebral arteries. Stroke 1979;10:306-9.

${ }^{7}$ Eklund B, Joretag T, Kaijser L. Dissimilar effects of prostacyclin on cardiac output and forearm blood flow in healthy man. Clin Physiology 1981;1:123-30.

${ }^{8}$ Pickard J, Tamura A, Stewart M, McGeorge A, Fitch W. Prostacyclin, indomethacin and the cerebral circulation. Brain Res 1980;197:425-31.

${ }^{9}$ Brandt L, Ljungeren B, Andersson K-E, Hindfelt B, Uski T. Effects of indomethacin and prostacyclin on isolated human pial arteries contracted by CSF from patients with aneurysmal SAH. $J$ Neurosurg 1981;55:877-83.

${ }^{10}$ Aitken V, Boullin DJ, Du Boulay GH. Actions of prostacyclin and cerebrospinal fluid from patients with subarachnoid haemorrhage on rat cerebral arteries in vivo. J Physiol (Lond) 1980;308:65P.

" Hallenbeck JM, Furlow TW. Prostaglandin $I_{2}$ and indomethacin prevent impairment of post-ischaemic brain reperfusion in the dog. Stroke 1979;10:629-37.

${ }^{12}$ Amano T, Meyer JS. Prostaglandins and human CBF control: effect of aspirin and indomethacin. J Cereb Blood. Flow Metab 1981;Suppl 1:S403-4.

${ }^{13}$ Pickard JD, Rose JE, Cooke MBD, Blair I McL, Strathdee A. The effect of salicylate on cerebral blood flow in man. Acta Neurol Scand 1977;56 Suppl 64:422-3. 
${ }^{14}$ Brown MM, Pickles H. Effect of epoprostenol (prostacyclin, $\mathrm{PGI}_{2}$ ) on cerebral blood flow in man. $J$ Neurol Neurosurg Psychiatry 1982;45:1033-6.

15 Rane A, Oelz O, Seyberth HW et al. Relation between the kinetics of indomethacin and its effects on prostaglandin synthesis and platelet aggregation. Clin Res 1977;25:10A.

${ }^{10}$ Thomas DJ, Zilkha E, Redmond Set al. An intravenous ${ }^{133} \mathrm{Xe}$ clearance technique for measuring cerebral blood flow. J Neurol Sci 1979;40:53-63.

${ }^{17}$ Hucker HB, Zacchei AG, Cox SV, Brodie DA, Cantwell NHR. Studies on the absorption, distribution and excretion of indomethacin in various species. $J$ Pharmacol Exp Ther 1966;153:237-49.

${ }^{18}$ Pickles HG, O'Grady J. Side effects occurring during administration of epoprostenol (prostacyclin, $\mathrm{PGI}_{2}$ ) in man. Br J Clin Pharmacol 1982;14:177-85.

${ }^{19}$ Vane JR. Inhibition of prostaglandin synthesis as a mechanism of action for aspirin like drugs. Nature 1971;231:232-5.

${ }^{20}$ Wennmalm $\AA$, Eriksson S, Hagenfeldt L, Law D,
Patrono C, Pinca E. Effect of prostaglandin synthesis inhibitors on basal and carbon dioxide stimulated cerebral blood flow in man. Advances in Prostaglandin, Thromboxane and Leukotriene Research. New York: Raven Press, 1982.

${ }^{21}$ Eriksson S, Hagenfeldt L, Law D, Patrono C, Pinca E, Wennmalm $\AA$. Effect of prostaglandin synthesis inhibitors on basal and carbon dioxide stimulated cerebral blood flow in man. Gen Pharmacol 1983;14:179-80.

${ }^{22}$ Olesen J, Paulson OB, Lassen NA. Regional cerebral blood flow in man determined by the initial slope of the clearance of intra arterially injected ${ }^{133} \mathrm{Xe}$. Stroke 1971;2:519-40.

${ }^{23}$ Cook PJ, Maidment CG, James IM, Hutton RA, Dandona P. Effect of prostacyclin on cardiac output and cerebral blood flow. Clin Sci 1982;62:17.

${ }^{24}$ Hassan S, Pickles H. Epoprostenol (prostacyclin, $\mathrm{PGI}_{2}$ ) increases apparent liver blood flow. Prostaglandins, Leukotrienes and Medicine 1983;10:449-54.

${ }^{25}$ Kaijser L, Joretag T, Eklund B (quoted in reference 7). 